\title{
A neural network approach to predicting price negotiation outcomes in business- to-business contexts
}

\author{
Dirk C. Moosmayer a, Alain Yee-Loong Chong ${ }_{a, *}$, Martin J. Liu a, Bjoern Schuppar b
}

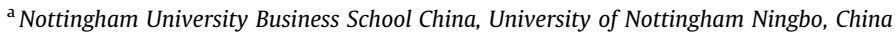

${ }^{\mathrm{b}}$ Schuppar Consulting Ltd. \&' Co. KG, Germany

\section{Keywords:}

Business-to-business marketing

Price negotiation

Neural network

Regression analysis

\begin{abstract}
A B S T R A C T
Price premiums are a key profit driver for long-term business relationships. For sellers in business-tobusiness (B2B) relationships, it is important to have appropriate strategies to negotiate price increases without trading off the relationships with their buyers. This paper aims to understand the annual price negotiation processes of companies by predicting whether a seller's reservation price, target price, and initial offer positively affect the price negotiation outcome between the sellers and buyers. Data from 284 B2B relationships of a chemicals supplier based in Germany was used to examine our research model. In order to capture the non-linear decisions that are involved in price negotiations and to address collinearity among negotiations' determinants, neural network analysis was used to predict the factors that influence price negotiation outcome. The neural network model was then compared with the results from regression analysis. Compared to regression analysis, the neural network has a lower standard error, and it showed that target price played a more important role in B2B price negotiations. The neural network was also able measure non-linear, non-compensatory decisions that are involved in price negotiations. The results imply that neural networks should be more widely used by researchers to address the threats that multi-collinearity poses. For companies, the results imply that price targets should be actively managed, e.g. through clear financial aims or through seminars aiming to help sales personnel toestablishmorechallenging negotiationaims.
\end{abstract}

\section{Introduction}

Price negotiations play an important role in business as their outcomes can impact long-term business relationships' profitability and the reputation of businesses (Carbonneau, Kersten, \& Vahidov, 2008). B2B price negotiations have various challenges such as the complex business environment which usually involves multiple interactions by at least two - and often many - people (Plank, 1997), and are therefore more complex than consumer price studies (Carbonneau et al., 2008; Holden \& Burton, 2008; Kotler \& Keller, 2006). Companies understandably also very rarely make their B2B pricing transparent or accessible due to its direct competitive profit relevance and often strategic character. For sales personnel who are preparing for annual price negotiations, it is difficult to know what price to demand (initial offer), what settlement to actually expect (target price), and what minimum price can be accepted before the relationship becomes unprofitable (reservation price). Price references (Mazumdar, Raj, \& Sinha, 2005) influence the negotiation behavior of both sellers and buyers and ultimately the price negotiation outcome.

\footnotetext{
* Corresponding author.

E-mail address: alain.chong@nottingham.edu.cn (A.Yee-Loong Chong).
}

Several conclusions can be drawn from existing studies of pricing negotiations, e.g. by Moosmayer, Schuppar, and Siems (2012) and Van Poucke and Buelens (2002). Firstly, existing studies in price negotiations are overly experimental (Krause, Terpend, \& Petersen, 2006), often using student samples, and transactional in nature. However, findings based on experimental designs account neither for context factors such as negotiators' expertise and experience, nor for the fact that the nature of industrial business is predominantly relationship-based, rather than transactional. The validity of experimental, transaction-oriented findings for price negotiations in B2B relationships thus appears questionable. Moreover, studies based on student sampling, although strong in internal validity (Bachrach \& Bendoly, 2011; Eckerd \& Bendoly, 2011), may suggest inappropriate business decisions due to limited external validity (Ketchen \& Hult, 2011; Stevens, 2011). Secondly, linear regression models are often chosen to examine the relationships between the determinants of price negotiations and their outcomes. However, regression models are preference regressions which assume that price negotiation decisions are linear compensatory models (Chong, 2013). Under this assumption, the shortfall in a negotiations decision such as reservation price can be compensated for by other factors such as initial offers or target price. However, given the complexities involved in price negotiations, linear 
regression models may not be able to capture all the non-compensatory decision rules involved in these processes, and as a result such models are deemed unreliable. Studies in other disciplines such as information systems have found that linear models tend to oversimplify the complexities involved in decisions (Chong, 2013; Venkatesh \& Goyal, 2010). Thirdly, a limitation of regression models is the assumption of independent determinants; however, the seller's price preferences in negotiations are often interdependent. This may result in high multi-collinearity in the data analysis thus affecting the reliability of the results.

This research has several objectives. Firstly, this study aims to understand the factors that can predict the price negotiation outcomes in B2B relationships. Variables such as a seller's reservation price, target price, and initial offer are examined to see if they predict price negotiation outcome. Secondly, this research aims to examine whether non-linear, non-compensatory decision models such as neural networks provide a better model fit and forecasting than linear regression models for predicting pricing negotiation outcomes. In order to achieve this, the results from the neural network will be compared with regression analysis. Lastly, based on the results, this research will suggest how companies can maintain profitable long term B2B relationships by managing sales personnel's trust in pricing negotiations, and how researchers can use neural networks to help address multi-collinearity issues.

\section{Previous research}

\subsection{Negotiations in a business-to-business context}

A defining characteristic of negotiations is that parties with opposing interests make a joint business decision, regularly directed to the purchase of a certain amount of a specific product or service at a specific price. Negotiations may be understood as processes that "bring two or more parties together to try to accomplish mutually beneficial outcomes, while meeting individual goals that may be at odds with the other negotiating parties' goals" (Swaidan, 2007: 163). More competitively, negotiations may be understood as "a process of potentially opportunistic interaction by which two or more parties, with some apparent conflict, seek to do better through jointly decided action than they could otherwise" (Lax \& Sebenius, 1986: 11). Prior research has primarily taken economic (Nash, 1950; Nash, 1953; Tversky \& Kahneman, 1991) and psychological (Barry \& Oliver, 1996; Brenner, Koehler, Liberman, \& Tversky, 1996; Oliver, Balakrishnan, \& Barry, 1994; Tversky \& Kahneman, 1981) perspectives.

The economic perspective on negotiations has been presented by Nash (1950). He assumed distributive bargaining conditions with each party aiming to maximize its own profit (Pruitt, 1983) and both parties knowing the preferences of the negotiation partner. In this context, Nash argued, negotiators who behave rationally would thus share the gains of negotiation equally and agree on the mid-point between the buyer's and seller's reservation prices as a price negotiation outcome; the so-called "Nash equilibrium". A further focus has thus been the determination of a party's reservation price. Empirically, some studies found support for the Nash equilibrium (White, Valley, Bazerman, Neale, \& Peck, 1994), but other research efforts did not (Neale \& Bazerman, 1991; Neale \& Bazerman, 1992). Furthermore, one might think that more individual aspects like personal ambition are neglected in these economic perspectives. Such aspects have been discussed in the psychological stream.

A particular focus in this context has been on the establishment of cognitive references and their application when evaluating an offer. Cost (Wilken, Cornelissen, Backhaus, \& Schmitz, 2010), the best alternative to a negotiated agreement (BATNA) (Fisher \&
Ury, 1981) as best sourcing alternative (Wang \& Zionts, 2008), and market price (Blount White, Thomas-Hunt, \& Neale, 1996; Kristensen \& Gaerling, 1997b; White et al., 1994) have been discussed as important references in price negotiations. For market price, empirical results are contradictory with some authors describing a significant impact on price negotiation outcome (Blount White et al., 1996) and others showing no influence (White et al., 1994). Moreover, it has been shown that negotiators although contradicting the assumption of rational behavior - are influenced by past experiences (e.g. prices paid in the past) as a reference (Diekmann, Tenbrunsel, Shah, Schroth, \& Bazerman, 1996).

In this paper, we aim to use a seller's references in order to explain B2B price negotiation outcome, i.e. the settlement price reached in price negotiations in continuous B2B relationships. Price negotiation outcome thus describes a percentage price increase compared to the previous year's price level fixed in a framework agreement. As references of the counterparty are usually inaccessible to a negotiator, we focus on only one negotiator's reference points. We focus on the seller side and accordingly we do not consider buyer's references in our model.

A broad range of reference points and their framing have been found to be relevant with regard to price negotiation outcomes (Bazerman, Magliozzi, \& Neale, 1985; Nagel \& Mills, 1989). We investigate the negotiation of price changes in annual reviews of B2B relationships. In this context, we focus on negotiators' reservation price, target price, and initial offer. We do so because these have been the focus of prior experimental research (Krause et al., 2006; Van Poucke \& Buelens, 2002). Moreover, their managerial relevance is high because these "reference points ... are determined before the negotiation" (Krause et al., 2006: 13) and managers could thus manipulate them in order to achieve better negotiation results. Finally, other references that have been discussed in the literature appear not to be relevant or inherent to the context: in the negotiations that were studied, sellers approached buyers with an initial offer; considering the intended initial offer as a distinct determinant as in Miles (2010) is thus not necessary. Similarly, past prices as discussed in Diekmann et al. (1996) are the basis to which negotiated price changes are applied and are thus reflected in each reference.

\subsection{References in price research}

The reference concept has been established in the psychological domain (Helson, 1964; Tversky \& Kahneman, 1992) and has been successfully applied to pricing issues (Mazumdar et al., 2005; Winer, 1986). Reference prices are individual price norms that are applied when judging a price observed in the market (Winer, 1988). Such references may have a predictive and normative function (Rajendran \& Tellis, 1994). The application of reference price theory has focused on the explanation of consumer brand choice and on the opportunity to guide consumer price perceptions during and after their purchases. Reference prices are commonly differentiated by their sources being internal (in other words based on memories of prior experiences or derived from the mind) or external (perceived in the decision-making situation, e.g. when shopping in a supermarket) (Mazumdar et al., 2005). The reference price concept has also been applied in B2B marketing (Moosmayer et al., 2012; Wilken et al., 2010) and beyond the marketing domain, such as in human resource management (Siems, Goelzner, \& Moosmayer, 2012) and in accounting (Mitter C. \& F., 2008). Conceptually, reference prices reflect expectations of acceptable adaptation levels (Monroe, 1973), normative considerations regarding fairness (Bolton, Warlop, \& Alba, 2003), aspiration perspectives (Klein \& Oglethorpe, 1987), and aspects of social context (Mezias, Chen, \& Murphy, 2002). 
In this investigation we consider the reservation price, that is, the lowest price at which a seller is willing to close a deal. Although it is a reference internal to the seller, the reservation price is still overly determined by aspects beyond the control of the negotiator, such as the company's cost base or the BATNA. The impact of reservation price on price negotiation outcome can be explained by range theory (Volkmann, 1951). Along with range theory, price stimuli are judged against their position within a range of acceptable prices. Reservation price constitutes the bottom of such a range. Some studies have found reservation prices to be an important determinant of the price negotiation outcome (Kristensen \& Gaerling, 1997a; White et al., 1994).

Target prices represent negotiators' price targets and thus constitute the best settlement a buyer or a seller can expect to achieve (Zetik \& Stuhlmacher, 2002). As such it constitutes an internal reference. The seller will judge any counter offer by the buyer primarily against this target. Kristensen and Gaerling (1997a) proposed that one party's target price reflects the estimate of the other party's reservation price. That is, a seller's target price would reflect the estimated maximum willingness to pay of the buying counterpart. Prospect theory (Kahneman \& Tversky, 1979) suggests that any price obtained below the reference is perceived as a loss, while prices obtained above it are perceived as gains. Also, losses are systematically overweighted (Baumeister, Bratslavsky, Finkenauer, \& Vohs, 2001; Skowronski \& Carlston, 1987). Therefore, any price below the references should cause dissatisfaction and invoke determined seller efforts to reach a price closer to the reference. In contrast, prices above the negotiator's own references are perceived as gains that do not merit aggressive tactics. Consequently, higher target prices may be expected to result in higher price negotiation outcomes. This is in line with research which has shown that negotiators with more ambitious goals, i.e. higher target prices, reach higher price negotiation outcomes (Huber \& Neale, 1986; Huber \& Neale, 1987; Lim, 1997; Pruitt, 1981; White \& Neale, 1994).

Initial offers (Galinsky \& Mussweiler, 2001; Raiffa, 1982) constitute references that may be used as a strategic informational cue given by the seller to the buyer. As the first price point, initial offers constitute an important element of negotiation and bargaining processes. Initial offers are determined by sellers before the negotiation begins (Krause et al., 2006). Research investigated initial offers as a trigger for a series of counter offers. The initial offer can be understood as a price anchor against which both parties adjust their own price references (Kahneman, 1992) and subsequently their counter offers. Accordingly, initial offers are very important for the outcome of competitive bargaining processes. For buyers, the initial offer is the first reference that requires a response. Hence, initial offers function as "anchors" or external references for the buyer. As strategic informational cues, initial offers affect the corresponding counter offer because they provide the person making the counter offer with additional information with which to reassess his or her intended offer (Kristensen \& Gaerling, 1997c; Liebert, Smith, Hill, \& Keiffer, 1968). Adoption level theory has been used to argue that this reference is perceived as a strong adoption level by the buyer whose counter offer must respond to this adoption level. For maintaining the negotiation, buyers are likely to provide a response, i.e. a counter offer, to which the negotiation partner can be expected to respond positively. In other words, higher initial offers raise the subsequent offers. Evidence shows that the stated first offer can affect the corresponding counter offer (Kristensen \& Gaerling, 1997c; Yukl, 1974) and ultimately the negotiation outcome (Pruitt \& Carnevale, 1993). Some research has even claimed initial offers to be the best predictors of price negotiation outcomes (Van Poucke \& Buelens, 2002).

As the extent to which a negotiator is able to translate his or her references into price negotiation outcomes might depend on the specific relationship context, particularly how profitable the relationship is (profitability of relationship) and how much business the company does with each buyer (size of relationship) (e.g. McHugh, Humphreys, \& McIvor, 2003 on power relationships), we consider these two influences as control variables and aim to evaluate the resulting model:

Model : $P_{\mathrm{NO}}=\beta_{0}+\beta_{R} P_{R}+\beta_{T} P_{T}+\beta_{I} P_{I}+\beta_{\mathrm{C} 1} P_{\mathrm{C} 1}+\beta_{\mathrm{C} 2} P_{\mathrm{C} 2}+\varepsilon$

with

$P_{\mathrm{NO}}=$ Price negotiation outcome

$P_{R}=$ Seller's reservation price

$P_{T}=$ Seller's target price

$P_{I}=$ Seller's initial offer

$P_{\mathrm{C}[1]}=$ Control 1: profitability of relationship

$P_{\mathrm{C}[2]}=$ Control 2: size of relationship

$\beta_{X}=$ Importance coefficients for determinant $X$

$\varepsilon=$ Error term

It is worth noting that the three price references that are considered might not be independent. Some authors have argued for conceptual interdependence between initial offer and target price (Kristensen \& Gaerling, 1997b). The direction of this influence is disputed, with some authors suggesting target price affects (Krause et al., 2006), and others suggesting it is affected by, the initial offer (Kristensen \& Gaerling, 1997b). Others have empirically identified substantial collinearity between all three references (Van Poucke \& Buelens, 2002).

Two approaches have been suggested to address this interdependence and the resulting multicollinearity in the context of price negotiations. One is to consider a single price reference and to use two additional, compound determinants, namely, the target zone (Blount White, Valley, Bazerman, Neale, \& Peck, 1994), which describes the difference between reservation and target price, and the offer zone (Van Poucke \& Buelens, 2002), which describes the difference between target price and initial offer. Analyzing dyadic data from 183 experimental negotiations with experienced negotiators in a fictitious context, Van Poucke and Buelens (2002) use initial offer as the most important reference and add the two zones to overcome multicollinearity. Nevertheless, this approach automatically attributes all "shared" variance to the one original price reference that is kept (here the initial offer). The approach thus does not help to clarify which determinant is actually most important but applies some untested assumptions. An alternative approach was presented by Moosmayer et al. (2012), addressing the multicollinearity issue in the price negotiation data with ridge regression. Ridge regression adds a constant term to the variables and thereby reduces standard errors at the expense of systematically biased estimates. In this analysis they found initial price offering and reduced target price to be of approximately equal weight. Through ridge regression they obtained statistically significant results; nevertheless, the impact of the included bias remained unclear.

To overcome the threat of potential multicollinearity, we aim to evaluate our model not only with regression analysis but also with neural networks. Multicollinearity seemed to occur because the price references appear to have some kind of shared floor. Because this floor is shared, it cannot be attributed to one of the price references. However, regression analysis does not allow accounting for such shared variance and is thus likely to misallocate this shared variance. Neural networks, in contrast, are not sensitive to multicollinearity, because they integrate a hidden layer between independent and dependent variables. Although neural networks do not allow any assumptions about the hidden layer, one might imagine that the variance shared by all three price determinants is accounted for in the hidden layer. Neural networks thus implicitly account for multicollinearity in the data and should make it possible to attribute more accurate importance weights to the 
three references. Statistically, neural network analysis thus constitutes an effective means to overcome the threat that multicollinearity poses to the application of regression analyses.

\subsection{Neural network overview}

A neural network (or artificial neural network) is a "massively parallel distributed processor made up of simple processing units, which have a natural propensity for storing experimental knowledge and making it available for use" (Haykin, 2001). A neural network is inspired by the way the human brain structured and how it acquires knowledge from its environment through a learning process (Tsai \& Wu, 2008). The knowledge acquired in a neural network input is stored by the interneuron connection strengths (Haykin, 2001). Despite being inspired by the function of the human neurological systems, the architectures as well as the processing elements in neural networks have gone beyond their biological inspirations (Chong, 2013; Svozil, Kvasnicka, \& Pospichal, 1997). A neural network is simply a statistical method which can be used to obtain a close approximation to a problem based on a particular observation (Sexton, Johnson, \& Hignite, 2002). Using historical data, a neural network is able to apply the learning process to modify its interneuron connection strengths (or weight coefficients) in an orderly manner to achieve the desired design objective (Sexton et al., 2002).

Neural network models are typically comprised of nodes or neurons that are ordered into hierarchical layers (see Fig. 1). The first layer is known as the input layer, the last layer is called the output layer, and the layers in between are called hidden layers (Chong, 2013). Data is received by the input layers, and the information and conclusions are produced in the output layers (Morris, Greer, Hughes, \& Clark, 2004). The neurons in each layer are connected to neurons in the following layer. Synaptic weights are given to each input (Bakar \& Tahir, 2009). These weights are transferred to the subsequent hidden layers which have several hidden neurons. The values in the hidden layer are then added through applied weights, and they are converted into an output value by a nonlinear activation function (see Svozil et al., 1997 for more details on activation functions). The weights obtained are passed to the neurons in the next layer, and provide a feed-forward path to the output layer (Sexton et al., 2002). The weight coefficients are adjusted through an iterative training process when the training samples are used to train the network. The weight coefficients show the degree of importance of a given connection in a neural network, (Svozil et al., 1997), and the trained knowledge is then stored for future predictive use.

Neural networks have several advantages when compared to the traditional linear statistical methods. A neuron is a non-linear device, and as a result, the neural network itself is non-linear. The non-linearity in neural networks is important as it allows for the investigation of relationships between inputs and outputs which are non-linear, e.g. in studying of non-compensatory deci-

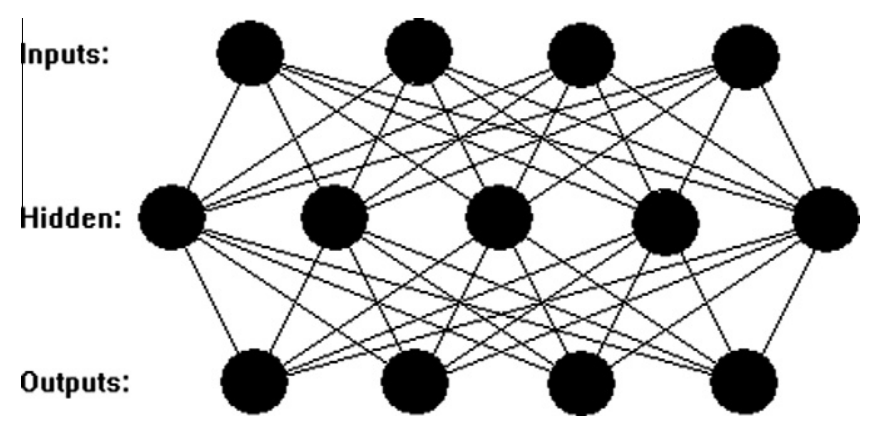

Fig. 1. Three layer network. sion processes (Svozil et al., 1997). Another advantage of the neural network is that its input and output mapping can be accomplished without meeting the assumptions of sample distribution which are often required in linear regression studies (Chiang, Zhang, \& Zhou, 2006; Garson, 1998). Neural networks are also found to have better prediction rates when compared to traditional compensatory models such as logistic, multiple, and discriminant regression analyses (Chiang et al., 2006; Garson, 1998). A neural network is also capable of adapting without much assistance from users.

Neural networks have been applied to various studies in economics (Kaastra \& Boyd, 1996), consumer choice (Chiang et al., 2006; Hu, Shanker, \& Hung, 1999), and customer loyalty (Hsu, Shih, Huang, Lin, \& Lin, 2009) and information systems adoptions (Chong, 2013). These studies showed that neural networks can be applied to broad areas of research, consistently providing good results. This study therefore employs a neural network to predict the factors that influence price negotiation outcomes in B2B relationships. The results from the neural network will then be compared to those obtained from multiple regression analysis in order to determine which approach offers better predictive power.

\section{Methodology}

\subsection{Approach}

In order to test the model we collected data on the European B2B sales activities of a global player in the chemical industry based in Germany. We chose the chemical industry due to its economic relevance and because it sells to clients in a diverse field of industries. In line with the recommendation to use the most qualified informants for gathering information on an issue under investigation (Kumar, Stern, \& Anderson, 1993), we invited the negotiating sales staff of the company to be our key informants. To reduce individual influences and to increase motivation to participate, all negotiators received sales training before starting the negotiation. The trained personnel conducted 645 negotiations and returned complete data for 284 negotiations, resulting in a $44 \%$ response rate. Considering managers' daily pressures and the confidentiality of the issue, this seems to be a satisfactory response rate. Moreover, the missing data was not correlated with other variable values in these observations and did thus not cause any systematic bias. Although the researchers have no precise information about non-successful negotiations, experiences with B2B supplier relationships in general and with this chemical supplier company in particular establish that non-closure is not a major issue.

\subsection{Data}

For each relationship we investigated, we collected the sellers' reservation price, target price and initial offer before the negotiation started. The price negotiation outcome was collected after the negotiation (see Table 1 for means and correlations). All these variables are manifest single item measures and describe relative price increases. For instance, a price negotiation outcome of .07 represents a $7 \%$ price increase compared to the existing framework agreement. Profitability and size of relationship were used as controls: both were provided by the negotiators. Profitability was measured as percentage portion of total revenue, i.e. 16 represents a $16 \%$ gross margin. Size of relationship was measured in total revenue in Euros.

\subsection{Multiple regression analysis}

We performed multiple regression analysis to determine how the different price references influence the eventual price 
Table 1

Means, standard deviations and correlations of measured price references.

\begin{tabular}{|c|c|c|c|c|c|c|c|}
\hline & \multirow[t]{2}{*}{ Mean } & \multirow[t]{2}{*}{ Std } & \multicolumn{5}{|l|}{ Correlation } \\
\hline & & & (1) & $(2)$ & (3) & (4) & (5) \\
\hline (1) Reservation price & 0.055 & 0.064 & & & & & \\
\hline (2) Target price & 0.075 & 0.081 & $0.911^{* * *}$ & & 0 & & \\
\hline (3) Initial offer & 0.097 & 0.097 & $0.888^{* * *}$ & $0.968^{* * *}$ & & & \\
\hline (4) Price negotiation outcome & 0.073 & 0.076 & $0.861^{* * *}$ & $0.925^{* * *}$ & $0.912^{* * *}$ & & \\
\hline (5) Size $^{a}$ & 0.336 & 0.629 & -0.110 & -0.115 & -0.112 & $-0.131^{*}$ & \\
\hline (6) Profitability & 0.423 & 0.224 & $-0.389^{* * *}$ & $-0.407^{* * *}$ & $-0.407^{* * *}$ & $-0.388^{* * *}$ & -0.005 \\
\hline
\end{tabular}

Note: STD: standard deviation.

a Measured in 1000,000 euro.

Table 2

Regression model with price references.

\begin{tabular}{|c|c|c|c|c|}
\hline & \multicolumn{4}{|c|}{$\begin{array}{l}\text { Regression model } \\
\text { S.E. of Estimate }=0.0284 \\
R^{2}=0.863 ; R_{a}^{2}=0.860\end{array}$} \\
\hline & $B$ & SE & $\beta$ & VIF \\
\hline Constant & 0.009 & 0.005 & & \\
\hline Reservation price & 0.117 & 0.064 & $0.098^{\text {n.s. }}$ & 16.0 \\
\hline Target price & 0.548 & 0.093 & $0.583 * * *$ & 19.9 \\
\hline Initial offering & .199 & 0.070 & $0.254 * *$ & 5.91 \\
\hline Size $^{\mathrm{a}}$ & -0.003 & 0.003 & $-0.025^{\text {n.s. }}$ & 1.02 \\
\hline Profitability & -0.003 & 0.008 & $-0.009^{\text {n.s. }}$ & 1.21 \\
\hline
\end{tabular}

a Measured in 1000,000 euro.

negotiation outcomes (see Table 2). To support the assumed linear relationship, each price reference was plotted against the price negotiation outcome without any non-linear relationship being identified. No auto-correlation was found based on Durbin-Watson scores. Heteroscedasticity was analyzed, based on plots of the residuals and no particularities were identified.

$R^{2}$ and adjusted $R^{2}$ are both .86 , i.e. the following model explained $86 \%$ of the variation in price negotiation outcomes reached by the negotiators of the chemical company in their dealings:

$P_{S}=.009+.117 P_{R}+.548 P_{T}+.199 P_{I}-.003 P_{\mathrm{C} 1}-.003 P_{\mathrm{C} 2}+\varepsilon$

Target price has the highest regression weight $(B=0.55)$ and thus appears to be the most important determinant; initial offer is less important $(B=0.20)$, while the influence of reservation price $(B=0.12)$ remains insignificant $(t=1.82)$. The limited significance of the result seems to be caused by relatively high standard errors, which can be traced back to substantial multi-collinearity in the data and resulting VIF scores as high as 19.9. This is in line with the expectations of a shared basis (Van Poucke \& Buelens, 2002). Hence, in order to overcome the threat that is imposed by multi- collinearity, we use neural network analysis as a non-compensatory approach to attributing importance to the determinants under consideration.

\subsection{Neural network analysis}

In order to examine the proposed model, a multilayer perceptron training algorithm was used to train the neural network. Cross validations were applied to prevent the model from overfitting. As indicated by previous studies by Sexton et al. (2002), Chong (2013) and Svozil et al. (1997), there is no heuristic for determining the hidden nodes in a neural network, and therefore a preliminary network was examined using 1-10 hidden nodes. This approach is consistent with previous work conducted by Chong (2013), Sexton et al. (2002), Morris et al. (2004) and Wang and Elhag (2007). The accuracy of the model was measured using the Root Mean Square Error (RMSE) over ten validations. Networks with four hidden nodes were found to be complex enough to map the datasets without incurring additional errors to the neural network model. The input layer consisted of the five price negotiation outcome predictors and the output layer consisted of one output variable which was the price negotiation outcome.

A ten-fold cross validation was performed whereby $90 \%$ of the data was used as the training net, while the remaining $10 \%$ was used to measure the prediction accuracy of the trained network. Table 3 shows the RMSE for the neural network.

When compared with the regression model, applying neural networks resulted in lower, i.e. better, RMSE values. The decrease in RMSE ranged between $11.4 \%$ and $18.4 \%$ and averaged $14.1 \%$. This shows that the non-linear neural network model is able to produce a better fit and forecast of the data when compared to the regression analysis. More importantly, the result demonstrates that a neural network model can capture the complex non-linear integrating effects in price negotiation decisions.

Table 3

RMSE for the neural networks.

RMSE from NN training sample RMSE from NN testing sample RMSE improvement of neural network compared to regression model $^{\mathrm{a}}$

\begin{tabular}{lllll} 
& & & Total & \% \\
\hline Neural network 1 & 0.0281 & 0.0233 & 0.0050 & 17.8 \\
Neural network 2 & 0.0281 & 0.0247 & 0.0036 & 12.8 \\
Neural network 3 & 0.0279 & 0.0248 & 0.0035 & 12.5 \\
Neural network 4 & 0.0281 & 0.0238 & 0.0045 & 16.0 \\
Neural network 5 & 0.0281 & 0.0230 & 0.0053 & 14.8 \\
Neural network 6 & 0.0280 & 0.0243 & 0.0040 & 14.4 \\
Neural network 7 & 0.0280 & 0.0243 & 0.0041 & 11.4 \\
Neural network 8 & 0.0281 & 0.0251 & 0.0032 & 13.3 \\
Neural network 9 & 0.0278 & 0.0246 & 0.0038 & 14.2 \\
Neural network 10 & 0.0280 & 0.0243 & 0.0040 & 14.5 \\
NN 1-10 Average & 0.0280 & 0.0242 & 0.0041 & \\
\hline
\end{tabular}

a Based on a comparison of the NN testing sample with the regression (RMSE $=0.0284$ ). 
Table 4

Relevant inputs to neural network model.

\begin{tabular}{lllllllllll}
\hline Variables & 1 & 2 & 3 & 4 & 5 & 6 & 7 & 8 & 9 & 10 \\
\hline Target price & $\mathrm{X}$ & $\mathrm{X}$ & $\mathrm{X}$ & $\mathrm{X}$ & $\mathrm{X}$ & $\mathrm{X}$ & $\mathrm{X}$ & $\mathrm{X}$ & $\mathrm{X}$ & $\mathrm{X}$ \\
Initial offering & $\mathrm{X}$ & $\mathrm{X}$ & $\mathrm{X}$ & $\mathrm{X}$ & $\mathrm{X}$ & $\mathrm{X}$ & $\mathrm{X}$ & $\mathrm{X}$ & $\mathrm{X}$ & $\mathrm{X}$ \\
Reservation Price & $\mathrm{X}$ & $\mathrm{X}$ & $\mathrm{X}$ & $\mathrm{X}$ & $\mathrm{X}$ & $\mathrm{X}$ & $\mathrm{X}$ & $\mathrm{X}$ & $\mathrm{X}$ & $\mathrm{X}$ \\
Size & & $\mathrm{X}$ & $\mathrm{X}$ & $\mathrm{X}$ & $\mathrm{X}$ & $\mathrm{X}$ & $\mathrm{X}$ & $\mathrm{X}$ & $\mathrm{X}$ & $\mathrm{X}$ \\
Profitability & & & & & & & & & & \\
\hline
\end{tabular}

Table 5

Sensitivity analysis.

\begin{tabular}{ll}
\hline Variable & Relative importance \\
\hline Target price & 1 \\
Initial offering & 0.2421 \\
Reservation price & 0.0283 \\
Size & 0.0011 \\
Profitability & 0 \\
\hline
\end{tabular}

Table 4 shows how often a specific predictor was included in the model for the ten different networks. For each input variable, an $\mathrm{X}$ in the table shows that there is at least one non-zero weight connecting it to a hidden node, thus implying that the predictor is relevant in predicting the price negotiation outcomes. Sensitivity analysis performance is shown in Table 4 .

The neural network is able to predict relationships between reservation price, target price, initial offer, profitability and size of relationship and price negotiation outcome. Based on the neural network analyses, target price is the most significant predictor of price preference, followed by initial offer, reservation price and size of relationship (see Table 5).

\section{Discussion}

We investigated negotiation outcomes in continuous B2B-relationships in the chemical industry and focused on the seller perspective. We found that $86 \%$ of the variation in price negotiation outcome was explained by the three price references considered: reservation price, target price and initial offer. This remarkably high explanatory power, together with the high correlations between all three price references and also the price negotiation outcome suggests two possible explanations. One is that industrial sellers have a very good sense of what to expect and thus adjust their references. Alternatively, one might assume that sellers, being the ones presenting the need for a price increase, are in a strong position and have a greater chance of achieving their internal expectations. Thus, the results suggest that experimental research designs underestimate the predictive power of a seller's target price, as experimental respondents are usually unfamiliar with the specific negotiation context and will thus start with an unrealistically large variance in their price references. This is in line with Hokey, LaTour, and Jones (1995)'s suggestion that product experience and involvement increase the predictive power of a negotiator's references.

With regard to the impact of each reference on price negotiation outcome, we have shown that a seller's target price is the best predictor of price negotiation outcomes. This is in contrast to prior experimental research that emphasized the importance of the initial offer, and economic research that recognized the importance of the reservation price to predicting negotiation outcome. We suggest that the lack of context in experimental research may have caused misleading results in earlier investigations, for example when two participants in an experiment negotiated on a product or service with which they lacked familiarity. A lack of strong internal references and a lack of confidence in the own target might thus have resulted in the overvaluation of the importance of the initial offer as anchor for the entire negotiation. Such bias was further emphasized by the transactional character of experiments. Accordingly, we have added to existing literature by analyzing real B2B negotiation data and finding that negotiators' target price is the most important predictor of $\mathrm{B} 2 \mathrm{~B}$ price negotiation outcome.

Applying a neural network method further allowed us to address multi-collinearity in a way that has not been explored previously. Prior approaches either applied compound zone measures that overestimated the importance of the arbitrarily chosen core reference, or used ridge regression which produces more significant results at the expense of systematically biased findings. In contrast to these inadequate approaches to dealing with multi-collinearity, neural networks constitute an approach that allowed us to account for non-linear and non-compensatory effects in the data and to produce important measures for each of the predictors that do not suffer from the invalidity threat of some of the suggested approaches to address collinearity in regression models.

\section{Conclusions and Implications}

This research examined the predictors of B2B price negotiation outcomes. Variables such as reservation price, target price, initial offering, profitability and size of relationship were examined in our proposed model. Using the predictive analytic approach provided by a neural network, this research examined B2B negotiations of a major chemical firm in Germany and its buyers. The results obtained from the neural network were then compared with multiple regression analysis. The neural network was able to solve the multi-collinearity bias as well as to provide better predictions than the regression model. This research has several implications.

Firstly, for companies, the results imply that it would be wise to support their sales personnel in setting ambitious targets and translating these into a specific target price for each negotiation. Concretely, companies could communicate an average target price, or a price target for each customer. Furthermore, training could explicitly aim to enable negotiators to establish ambitious price targets and to defend them in a negotiation. Wilken et al. (2010) have found that providing transparent cost information to negotiators can lead to more favorable outcomes for the company. It might similarly be effective for a company to convey a better understanding to its negotiators of how potential price negotiation outcomes are connected to the firm's financial performance. For the individual sales representative, results generally suggest that expecting a little more might also result in a little more. In particular, this requires solid preparation with a clear target to be achieved.

Secondly, the results explained variation in price negotiation outcome better that existing experimental research. Thus, relying on experimental data that overemphasizes the importance of the initial offer appears to be misleading. Using market data from business negotiations seems crucial for avoiding poor managerial decisions based on overly biased findings.

Thirdly, this research showed that neural networks can be used as a means to overcome multicollinearity issues in data. In price negotiation studies where the predictors could be highly correlated, neural network analysis allows us to predict the outcomes with less error. Our research thus suggests that neural network method may be applied to broader range of business research problems where multicollinearity may be an issue.

\section{Limitations}

There are several limitations in this study. Firstly, as price negotiation studies have often been conducted using experimental 
approaches, it may be useful to integrate experimental data with data collected from actual negotiations to study the predictors of B2B negotiations. Secondly, other variables such as individual characteristics (e.g. gender or personal ambition) and collective characteristics (e.g. team size or cultural and national context) can be included to improve the research model. Finally, we expect that a dyadic approach with an analysis of both parties' (e.g. buyers and sellers) references may reveal some new insights.

\section{References}

Bachrach, D. G., \& Bendoly, E. (2011). Rigor in behavioral experiments - a basic primer for supply chain management researchers. Journal of Supply Chain Management, 47(3), 5-8.

Bakar, N. M. A., \& Tahir, I. M. (2009). Applying multiple linear regression and neural network to predict bank performance. International Business Research, 2(4), 176-183.

Barry, B., \& Oliver, R. L. (1996). Affect in negotiation: A model and propositions. Organizational Behavior and Human Decision Processes, 67(2), 127-143.

Baumeister, R. F., Bratslavsky, E., Finkenauer, C., \& Vohs, K. D. (2001). Bad is stronger than good. Review of General Psychology, 5(4), 323-370.

Bazerman, M. H., Magliozzi, T., \& Neale, M. A. (1985). Integrative bargaining in a competitive market. Organizational behavior and human Decision Processes, 34(3), 294-313.

Blount White, S., Thomas-Hunt, M. C., \& Neale, M. A. (1996). The price is right - or is it? A reference point model of two-party price negotiations. Organizational Behavior and Human Decision Processes, 68(1), 1-12.

Blount White, S., Valley, K., Bazerman, M. H., Neale, M. A., \& Peck, S. (1994). Alternative models of price behavior in dyadic negotiations: Market prices, reservation prices, and negotiator aspirations. Organizational Behavior and Human Decision Processes, 57(3), 430-477.

Bolton, L. E., Warlop, L., \& Alba, J. W. (2003). Consumer perceptions of price (Un) fairness. Journal of Consumer Research, 29(4), 474-491.

Brenner, L. A., Koehler, D. J., Liberman, V., \& Tversky, A. (1996). Overconfidence in probability and frequency judgments: A critical examination. Organizational Behavior and Human Decision Processes, 65(3), 212-219.

Carbonneau, R., Kersten, G. E., \& Vahidov, R. (2008). Predicting opponent's moves in electronic negotiations using neural networks. Expert Systems with Applications, 34(2), 1266-1273.

Chiang, W. K., Zhang, D., \& Zhou, L. (2006). Predicting and explaining patronage behavior toward web and traditional stores using neural networks: A comparative analysis with logistic regression. Decision Support Systems, 41(2), 514-531.

Chong, A. Y. L. (2013). Predicting m-commerce adoption determinants: A neural network approach. Expert Systems with Applications, 40(2), 523-530.

Diekmann, K. A., Tenbrunsel, A. E., Shah, P. P., Schroth, H. A., \& Bazerman, M. H. (1996). The descriptive and prescriptive use of previous purchase price in negotiations. Organizational Behavior and Human Decision Processes, 66(2), 179-191.

Eckerd, S., \& Bendoly, E. (2011). Introduction to the discussion forum on using experiments in supply chain management research. Journal of Supply Chain Management, 47(3), 3-4.

Fisher, R. \& Ury, W. (1981), Getting to yes, Houghton-Mifflin, Boston, MA.

Galinsky, A. D., \& Mussweiler, T. (2001). First offers as anchors: The role of perspective-taking and negotiator focus. Journal of Personality and Social Psychology, 81(4), 657-669.

Garson, G. D. (1998), Neural networks: An introductory guide for social scientists, Sage Thousand Oaks, CA.

Haykin, S. (2001), Neural networks: A comprehensive foundation, Prentice Hall. Helson, H. (1964). Adaption level theory. New York: Harper and Row.

Hokey, M., LaTour, M. S., \& Jones, M. A. (1995). Negotiation outcomes: The impact of the initial offer, time, gender, and team size. International Journal of Purchasing and Materials Management, 31(4), 19-24.

Holden, R. K., \& Burton, M. R. (2008). Pricing with confidence. 10 ways to stop leaving money on the table. Hoboken, NJ: Wiley.

Hsu, C. I., Shih, M. L., Huang, B. W., Lin, B. Y., \& Lin, C. N. (2009). Predicting tourism loyalty using an integrated Bayesian network mechanism. Expert Systems with Applications, 36(9), 11760-11763.

Hu, M. Y., Shanker, M., \& Hung, M. S. (1999). Estimation of posterior probabilities of consumer situational choices with neural network classifiers. International Journal of Research in Marketing, 16(4), 307-317.

Huber, V. L., \& Neale, M. A. (1986). Effects of cognitive heuristics and goals on negotiator performance and subsequent goal setting. Organizational Behavior and Human Decision Processes, 38(3), 342-365.

Huber, V. L., \& Neale, M. A. (1987). Effects of self and competitor goals on performance in an interdependent bargaining task. Journal of Applied Psychology, 72(2), 197-203.

Kaastra, I., \& Boyd, M. (1996). Designing a neural network for forecasting financial and economic time series. Neurocomputing, 10(3), 215-236.

Kahneman, D. (1992). Reference points, anchors, norms, and mixed feelings. Organizational Behavior and Human Decision Processes, 51(2), 296-312.

Kahneman, D., \& Tversky, A. (1979). Prospect theory: An analysis of decision under risk. Econometrica, 47(2), 263-291.
Ketchen, D. J., Jr., \& Hult, G. T. M. (2011). Building theory about supply chain management: Some tools from the organizational sciences. Journal of Supply Chain Management, 47(2), 12-18.

Klein, N. M., \& Oglethorpe, J. E. (1987). Cognitive reference points in consumer decision making. Advances of Consumer Research, 14(1), 183-187.

Kotler, P., \& Keller, K. L. (2006). Marketing management (12th ed.). Upper Saddle River, NJ: Pearson.

Krause, D. R., Terpend, R., \& Petersen, K. (2006). Bargaining stances and outcomes in buyer-seller negotiations: Experimental results. The Journal of Supply Chain Management, 42(3), 4-15.

Kristensen, H., \& Gaerling, T. (1997a). Determinants of buyers' aspiration and reservation price. Journal of Economic Psychology, 18(5), 487-503.

Kristensen, H., \& Gaerling, T. (1997b). The effects of anchor points and reference points on negotiation process and outcome. Organizational Behavior and Human Decision Processes, 71(1), 85-94.

Kristensen, H., \& Gaerling, T. (1997c). Adoption of cognitive reference points in negotiations. Acta Psychologica, 97(3), 277-288.

Kumar, N., Stern, L. W., \& Anderson, J. C. (1993). Conducting interorganizational research using key informants. Academy of Management Review, 36(6), 1633-1651.

Lax, D. A., \& Sebenius, J. K. (1986). The manager as negotiator: Bargaining for cooperation and competitive gain. New York: The Free Press.

Liebert, R. M., Smith, W. P., Hill, J. H. \& Keiffer, M. (1968). The effects of information and magnitude of initial offer on interpersonal negotiation. Journal of Experimental Psychology, 4(4), 431-441.

Lim, R. G. (1997). Overconfidence in negotiation revisited. International Journal of Conflict Management, 8(1), 52-79.

Mazumdar, T., Raj, S. P., \& Sinha, I. (2005). Reference price research: Review and propositions. Journal of Marketing, 69(4), 84-102.

McHugh, M., Humphreys, P., \& Mclvor, R. (2003). Buyer-supplier relationships and organizational health. Journal of Supply Chain Management, 39(2), 15-25.

Mezias, S. J., Chen, Y.-R., \& Murphy, P. R. (2002). Aspiration-level adaptation in an American financial services organization: A field study. Management Science, 48(10), 1285-1300.

Miles, E. W. (2010). Gender differences in distributive negotiation: When in the negotiation process do the differences occur? European Journal of Socia Psychology, 40(7), 1200-1211.

Mitter C. \& Siems, F. (2008), Transfer pricing for internal services and products - the link between accounting and marketing. In Rothenberger, S., Siems, F. (Eds.), Pricing perspectives. Marketing and management implications of new theories and applications, Palgrave Macmillan: Hampshire.

Monroe, K. B. (1973). Buyers' subjective perceptions of price. Journal of Marketing Research, 10(1), 70-80.

Moosmayer, D. C., Schuppar, B., \& Siems, F. U. (2012). Understanding price negotiation outcomes in business-to-business relationships - an empirica perspective from the chemical industry. Journal of Supply Chain Management 48(1), 92-106.

Morris, S. A., Greer, T. H., Hughes, C., \& Clark, W. J. (2004). Prediction of CASE adoption: A neural network approach. Industrial Management and Data Systems, 104(2), 129-135.

Nagel, S. S., \& Mills, M. K. (1989). Multicriteria dispute resolution through computer-aided mediation software. Mediation Quarterly, 7(2), 175-189.

Nash, J. F. (1950). The bargaining problem. Econometrica, 18(2), 155-162.

Nash, J. F. (1953). Two-person cooperative games. Econometrica, 21(1), 128-140

Neale, M. A., \& Bazerman, M. H. (1991). Cognition and rationality in negotiation. New York: The Free Press.

Neale, M. A., \& Bazerman, M. H. (1992). Negotiating rationally: The power and impact of the negotiator's frame. Academy of Management Executive, 6(3), 42-51.

Oliver, R. L., Balakrishnan, P. V. S., \& Barry, B. (1994). Outcome satisfaction in negotiation: A test of expectancy disconfirmation. Organizational Behavior and Human Decision Processes, 60(2), 252-275.

Plank, R. E. (1997). Theory, practice, and empirical development contributions: Advances in business marketing and purchasing. Journal of Business Research, 38(3), 235-241.

Pruitt, D. G. (1981). Negotiation behavior. New York: Academic Press.

Pruitt, D. G. (1983). Strategic choice in negotiation. American Behavioral Scientist, 27(2), 167-194

Pruitt, D. G., \& Carnevale, P. J. (1993). Negotiation in social conflict. Buckingham, UK: Open University Press and Pacific Grove.

Raiffa, H. (1982), The art and science of negotiation, Belknap Press of Harvard University Press, Cambridge, MA.

Rajendran, K. N., \& Tellis, G. J. (1994). Contextual and temporal components of reference price. Journal of Marketing, 58(1), 22-34.

Sexton, R. S., Johnson, R. A., \& Hignite, M. A. (2002). Predicting internet/e-commerce use. Internet Research, 12(5), 402-410.

Siems, F. U., Goelzner, H., \& Moosmayer, D. C. (2012). Reference compensation: A transfer of reference price theory to human resource management. Review of Managerial Science, 6(2), 103-129.

Skowronski, J. J., \& Carlston, D. E. (1987). Social judgment and social memory: The role of cue diagnosticity in negativity, positivity, and extremity biases. Journal of Personality and Social Psychology, 52(4), 689-699.

Stevens, C. K. (2011). Questions to consider when selecting student samples. Journal of Supply Chain Management, 47(3), 19-21.

Svozil, D., Kvasnicka, V., \& Pospichal, J. (1997). Introduction to mult-layer feedforward neural networks. Chemometrics and Intelligent Laboratory Systems, 39(1), 43-62. 
Swaidan, Z. (2007). Culture and negotiation ethics. Review of Business Research, 7(5), $162-171$.

Tsai, C. F., \& Wu, J. W. (2008). Using neural network ensembles for bankruptcy prediction and credit scoring. Expert Systems with Applications, 34(4) 2639-2659.

Tversky, A., \& Kahneman, D. (1981). The framing of decisions and the psychology of choice. Science, 211(4481), 453-458.

Tversky, A., \& Kahneman, D. (1991). Loss aversion in riskless choice. A referencedependent model. The Quarterly Journal of Economics, 106(4), 1039-1061.

Tversky, A., \& Kahneman, D. (1992). Advances in prospect theory: Cumulative representation of uncertainty. Journal of Risk and Uncertainty, 5(4), 297-323.

Van Poucke, D., \& Buelens, M. (2002). Predicting the outcome of a two-party price negotiation: Contribution of reservation price, aspiration price and opening offer. Journal of Economic Psychology, 23(1), 67-76.

Venkatesh, V., \& Goyal, S. (2010). Expectation disconfirmation and technology adoption: Polynomial modeling and response surface analysis. MIS Quarterly, 34(2), 281-303

Volkmann, J. (1951). Scales of judgment and their implications for social psychology. In J. H. Rohrer \& M. Sherif (Eds.), Social psychology at the crossroads (pp. 273-294). New York: Harper and Row.

Wang, Y. M., \& Elhag, T. (2007). A comparison of neural network, evidential reasoning and multiple regression analysis in modelling bridge risks. Expert Systems with Applications, 32(2), 336-348.
Wang, J., \& Zionts, S. (2008). Negotiating wisely: Considerations based on MCDM/ MAUT. European Journal of Operational Research, 188(1), 191-205.

White, S. B., \& Neale, M. A. (1994). The role of negotiator aspirations and settlement expectancies on bargaining outcomes. Organizational Behavior and Human Decision Processes, 57(2), 303-317.

White, S. B., Valley, K. L., Bazerman, M. H., Neale, M. A., \& Peck, S. R. (1994). Alternative models of price behavior in negotiations: Market prices, reservation prices, and negotiator aspirations. Organizational Behavior and Human Decision Processes, 57(3), 430-447.

Wilken, R., Cornelissen, M., Backhaus, K., \& Schmitz, C. (2010). Steering sales reps through cost information: An investigation into the black box of cognitive references and negotiation behavior. International Journal of Research in Marketing, 27(1), 69-82.

Winer, R. S. (1986). A reference price model of brand choice for frequently purchased products. Journal of Consumer Research, 13(2), 250-256.

Winer, R. S. (1988). Behavioral perspective on pricing: Buyers' subjective perceptions of price revisited. In T. M. Devinney (Ed.), Issues in pricing: Theory and research. Lexington: Lexington Books.

Yukl, G. A. (1974). Effects of the opponent's initial offer, concession magnitude, and concession frequency on bargaining behavior. Journal of Personality and Social Psychology, 30(3), 323-335.

Zetik, D. C., \& Stuhlmacher, A. F. (2002). Goal setting and negotiation performance. A meta-analysis. Group Process and Intergroup Relations, 5(1), 35-52. 